\title{
Diabetes as the risk of cancer: a literature review
}

\section{Theodore Dharma Tedjamartono*}

Faculty of Medicine, Udayana University, Bali, Indonesia

Received: 11 January 2021

Accepted: 08 February 2021

\section{*Correspondence:}

Dr. Theodore Dharma Tedjamartono,

E-mail: theodoredharma @yahoo.com

Copyright: () the author(s), publisher and licensee Medip Academy. This is an open-access article distributed under the terms of the Creative Commons Attribution Non-Commercial License, which permits unrestricted non-commercial use, distribution, and reproduction in any medium, provided the original work is properly cited.

\begin{abstract}
Cancer is a non-communicable disease with high mortality and morbidity rates. Data recorded by GLOBOCAN in 2018 shows the number of cancer patients is reached 18 million people with a death rate of 9 million people and predicted to increase every year. Diabetes is known to affect morbidity and mortality in cancer patients through increasing cancer cell proliferation and the risk of metastasis. This literature study not only explains the epidemiology, but also the mechanisms underlying the association of diabetes to cancer in general. Literature search was done using four search engines from PubMed, ProQuest, Science Direct and Google Scholar in the last 5 year, but relevant older articles were included. Cancer occurs due to the carcinogenesis process. This process is complex, where normal cells do not immediately mutate and become cancer cells but through several stages. The possible mechanisms underlying carcinogenesis in diabetic patients are hyperglycaemia, hyperinsulinemia, chronic inflammation, genetic variation, obesity, and hyperlactatemia. Examination of sugar levels in cancer patients, as well as cancer screening in patients with diabetes need to be done to detect early events and reduce morbidity and mortality.
\end{abstract}

Keywords: Insulin resistance, Hyperglycaemia, Carcinogenesis, Malignancy

\section{INTRODUCTION}

Cancer is one of the leading causes of death in the world. The number of cancer patients recorded in 2018 by GLOBOCAN was 18.1 million with the number of deaths was 9.6 million. ${ }^{1,2}$ The causes of cancer are divided into non modifiable risk factors such as due to genetic mutations, age, gender, race/ethnicity or modifiable risk factors such as smoking, alcohol, physical activity, diet, and obesity. The high incidence of cancer is also associated with several factors such as socioeconomic and lifestyle. ${ }^{2}$ In addition to these factors, several studies have linked diabetes and cancer incidence. Diabetes is associated with high morbidity and mortality in cancer patients, especially type 2 diabetes. $^{3}$

Diabetes is still a big challenge for decades with 460 million cases or it can be said that 1 in 11 people aged 20-70 years diagnosed with diabetes and it is predicted to reach 640 million cases by $2040 .{ }^{4}$ Diabetes categorized as type 1, type 2, gestational diabetes mellitus and specific types of diabetes due to other causes. ${ }^{5}$ While cancer is classified based on its anatomical location (e.g. lung, breast, liver, lymphoma, leukemia, and others) and there may be several subtypes (e.g. leukemia, breast). ${ }^{6}$ Diabetes shares some similar risk factors as cancer such as age, gender, race/ethnicity, diet, physical activity, smoking and alcohol. ${ }^{7,8}$

Correlation of diabetes and cancer was reported in a meta-analytic study from Vigneri et al with a result of patients with diabetes (especially type 2) showed a tendency to develop cancer. ${ }^{9}$ Patients with diabetes are said to be 2 times more likely to develop pancreatic, liver and endometrial cancer, while in breast, colon and bladder cancer are 1.2-1.5 times. ${ }^{6}$ Similar results was shown by Iliana et al that diabetes is 3 times more likely to develop into pancreatic cancer. ${ }^{10}$ Research by Katri et 
al shows that type 2 diabetes has a $70 \%$ risk of increasing the incidence of pancreatic cancer, 3 times more likely to develop liver cancer in men and 2 times in women. ${ }^{11}$ Study by Ballotari et al also shows that patients with diabetes have an increased risk of liver, bladder, pancreatic.

\section{METHODS}

Diabetes can be a risk factor for cancer through several mechanisms. This literature study not only describes the epidemiology of diabetes in cancer patients but biological factor related to cancer in general. Literature search was done using four search engines from PubMed, ProQuest, Science Direct and Google Scholar in the last 5 years, but relevant older articles were included. The search was conducted with keywords: malignancy or cancer or tumor and diabetes or diabetes mellitus or diabetes type 1 or diabetes type 2 and hyperglycemia or hyperinsulinemia or insulin resistance.

\section{DISCUSSION}

\section{Diabetes and Cancer}

Cancer is a non-communicable disease with the highest mortality rate in patients under the age of 70 in 2015 in more than half of the countries in the world. The cause of this high mortality rate is related to age and complications. (Freddie, 2020) The cause of cancer depends on each type, but basically occurs due to the carcinogenesis process. Carcinogenesis is a complex process which cells do not easily mutate and become cancer cells but undergo through several stages. Carcinogenesis occurs due to a combination of factors such as physical, biological, chemical and genetic. ${ }^{13}$ One of the factors that can cause carcinogenesis is diabetes. ${ }^{14}$

Diabetes type 1, also known as insulin dependent diabetes, occurs due to autoimmune or idiopathic damage to pancreatic beta cells. Diabetes type 2 or non-insulin dependent diabetes is the most common type with 90$95 \%$ of all types of diabetes. Diabetes type 2 occurs due to insulin resistance; therefore, insulin level can be normal or increased. Gestational diabetes mellitus (GDM) is diagnosed at 24-28 weeks of gestation in patients with no prior history of diabetes. Diabetes can be diagnosed based on plasma glucose criteria, either a fasting plasma glucose value or a 2 hours plasma glucose value during an oral glucose tolerance test or an A1C levels. 5

Several studies showed that patients with diabetes have a tendency to develop cancer later. Ballotari et al reporterd that the risk of cancer can appear in patients with a history of diabetes for at least 2 years and is highest at 610 years and then decreases thereafter. ${ }^{12}$ In contrast, research by Cuiping et al showed that the highest risk to developed cancer is history of diabetes more than 20 years with $70.4 \%$ followed by $10-19$ years with $19.9 \%$ and under 10 years with $9.6 \% .^{1}$

Research by Katri et al on 74.000 cancer patients with a history of diabetes type 2 shows that cancer can occur not only in the pancreas or liver, which are organs associated with diabetes but in all organs. ${ }^{11}$ A cohort study on 407.000 cancer patients in Italy by Ballotari et al showed $23.300(5.7 \%)$ samples had a history of diabetes which was dominated by type 2 diabetes with $96 \% .{ }^{12}$ Study by Wang et al explains the epidemiological and biological relationship between diabetes in several types of cancer, which suggests it may be caused by several factors including the similarity in risk factors for both diseases, or conditions related to diabetes such as insulin resistance, hyperglycemia, pro-inflammatory cytokines, and sex hormones. ${ }^{15}$

\section{Association between diabetes and cancer}

Diabetes increases the risk of cancer with the highest risk recorded is pancreatic cancer (82\%)(16), cholangiocarcinoma $(60 \%)$, colorectal $(35 \%)$ and breast $(25 \%) .{ }^{17-19}$

\section{Table1: Association between diabetes and types of cancer.}

\begin{tabular}{|c|c|}
\hline $\begin{array}{l}\text { Types of } \\
\text { cancer }\end{array}$ & Possible association with diabetes \\
\hline Gliom & Genetic variants \\
\hline Thyroid & $\begin{array}{l}\text { Hyperinsulinemia, chronic } \\
\text { Inflammation }\end{array}$ \\
\hline Pancreas & Inflammation \\
\hline Liver & $\begin{array}{l}\text { Hyperinsulinemia, chronic } \\
\text { inflammation, genetic variants }\end{array}$ \\
\hline Lung & $\begin{array}{l}\text { Hyperinsulinemia, chronic } \\
\text { inflammation, genetic variants }\end{array}$ \\
\hline Breast & $\begin{array}{l}\text { Hyperinsulinemia, chronic } \\
\text { inflammation, genetic variants } \\
\text { obesity }\end{array}$ \\
\hline Bladder & $\begin{array}{l}\text { Hyperinsulinemia, chronic } \\
\text { inflammation }\end{array}$ \\
\hline Ovarium & $\begin{array}{l}\text { Hyperinsulinemia, chronic } \\
\text { inflammation }\end{array}$ \\
\hline Endometrium & Hyperinsulinemia \\
\hline Cervix & Hyperinsulinemia \\
\hline Prostat & Genetic, genetic variants, obesity \\
\hline Colorectal & $\begin{array}{l}\text { Hyperglycemia, hyperinsulinemia, } \\
\text { chronic inflammation, genetic } \\
\text { variants }\end{array}$ \\
\hline
\end{tabular}

Pancreatic cancer and diabetes have a bidirectional relationship, pancreatic cancer can cause new onset diabetes, whereas diabetes can lead to pancreatic cancer. 


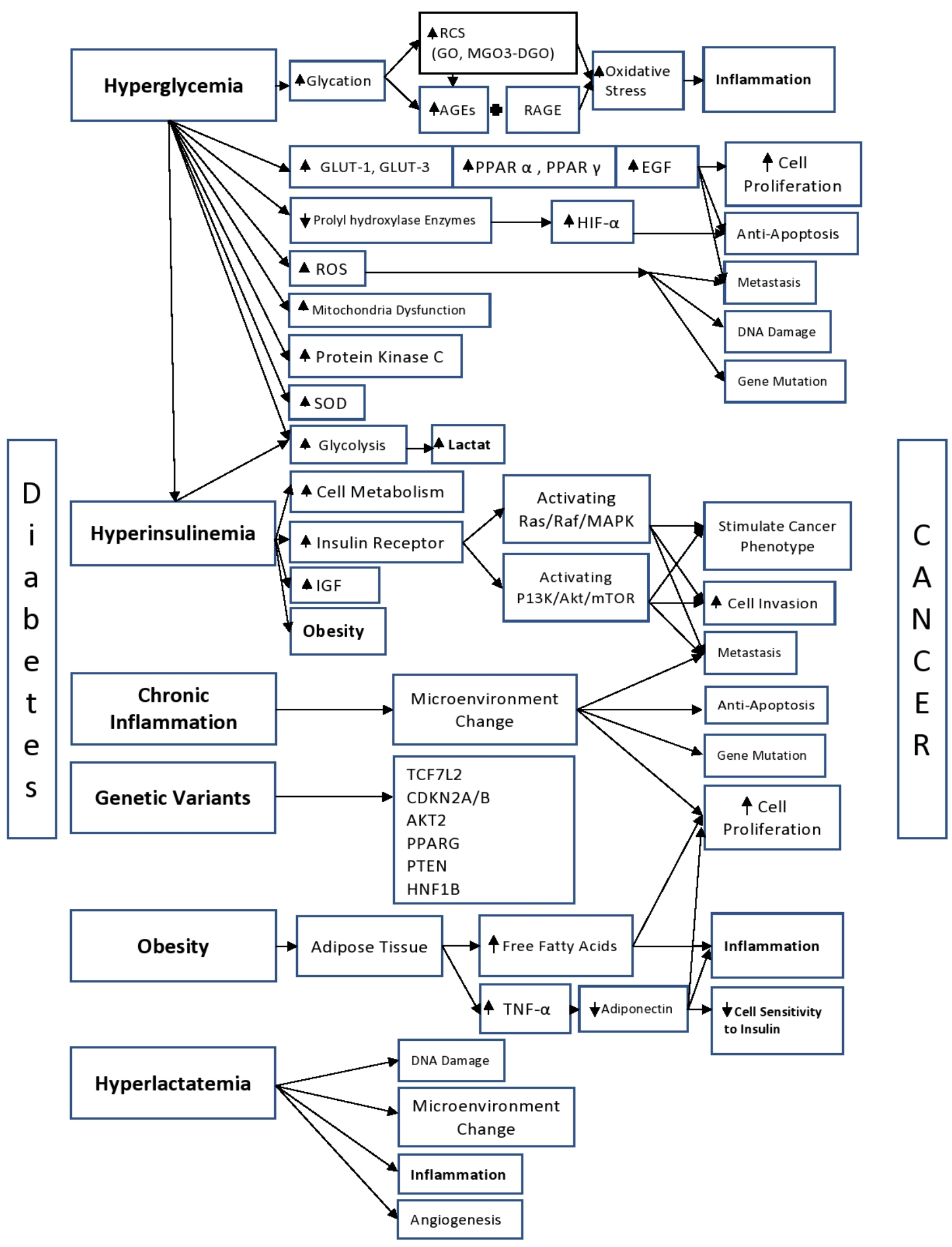

Figure 1: Mechanism of diabetes induced carcinogenesis. 
As explained that cancer is diagnosed based on its anatomical location, in type 2 diabetes there will be damage to the beta cells of the pancreas, inflammation in these cells will cause changes in the micro environment leading to cell mutation. Meanwhile, new onset diabetes in pancreatic cancer occurs due to paraneoplastic phenomena due to adrenomedullin secretion which inhibits insulin secretion. ${ }^{3}$ The possible association between diabetes and types of cancer and diagram of the correlation between diabetes and cancer can be seen in (Table 1) and (Figure 1).

\section{Hyperglycemia}

Diabetes is a metabolic disorder characterized by hyperglycemia, which is one of the factors that play a role in developing cancer. Generally, cells obtain energy through the tricarboxylic acid cycle, but in cancer cells, Warburg effect is known, which explains that cells will increase glucose uptake and rely on aerobic glycolysis to produce energy. ${ }^{20}$ Hyperglycemia will accelerate the glycation reaction leads to the formation of reactive carbonyl species (RCS) and advanced glycation endproducts (AGEs). RCS consists of glyoxal (GO), methylglyoxal (MGO) and 3-deoxyglucosone (3-DGO) which are known to affect oxidative stress in cells. The RCS itself is also said to contribute to the formation of AGEs. AGEs are found to be elevated in both type 1 and 2 diabetes. AGEs will bind to the receptor for advanced glycation end prodcuts (RAGE). The AGE-RAGE bond is said to be involved in inflammatory-related diseases including diabetes, atherosclerosis and cancer. ${ }^{21}$

Hyperglycemia express other factors such as are glucose receptors (GLUT-1, GLUT-3), Peroxisome Proliferatoractivated receptor (PPAR) $\alpha$ and $\gamma$, and eptithelial growth factor (EGF) which can increase proliferative activity, anti-apoptosis. and metastasis. ${ }^{22}$ Hyperglycemia will reduce the production of the enzyme prolyl hydroxylase, where the function of this enzyme is to eliminate hypoxia inducible factor $\alpha$ (HIF- $\alpha)$. HIF- $\alpha$ plays a role in antiapoptosis of cancer cells. ${ }^{23}$

Hyperglycemia will also induce the formation of insulin, growth factors and the secretion of proinflammatory cytokines which support cancer cell proliferation, metastasis and the ability to avoid apoptosis. ${ }^{24}$ This is supported by a meta-analysis by $\mathrm{Xu}$ et al on 35 studies which showed that glucose metabolism, including hyperglycemia and hyperinsulinemia will increase the risk of colon cancer. ${ }^{25}$ Hyperglycemia condition can accelerates mitochondrial dysfunction and forms free radicals and other reactive molecules such as protein kinase C, suporxide dismutase (SOD), and reactive oxygen species (ROS). ${ }^{23,26}$ Apart from damaging DNA, ROS also causes genetic mutations and triggers the activation of protein kinase and p21 activated kinase leading to metastasis. ROS is also able to bind to protein kinase $\mathrm{C}$ and protein tyrosine phosphatase, which are key molecules involved in cancer cell invasion and help cancer cells to adapt to the environment. ${ }^{27}$

\section{Hyperinsulinemia}

Insulin is a hormone that plays a major role in regulating carbohydrate and fat metabolism by increasing glucose absorption. In diabetes, insulin loses its function to increase glucose uptake and utilization. In response to this condition, pancreatic beta cells release more insulin as compensation and hyperinsulinemia will occur. ${ }^{28}$ Hyperinsulinemia can also lead to the development of cancer cells directly, especially in type 2 diabetes by affecting cell metabolism and indirectly through protumoral effects through abnormal stimulation of the oncogenic signalling pathway and increasing growth factor-dependent cell proliferation. ${ }^{21}$ Some cancer cells are said to express insulin receptors including Isoform A and Insulin Growth Factor (IGF). Isoform A receptors are capable of stimulating insulin-mediated mitogenesis, even in cells deficient in IGF receptors. ${ }^{29}$

Insulin receptors are also able to stimulate proliferation and metastasis in cancer cells. After the insulin receptor or IGF interacts with its ligands it will activate several signalling pathways including Ras/Raf/MAPK and P13K/Akt/mTOR (30-33) and will stimulate several cancer phenotypes including proliferation, protection from apoptotic stimuli, invasion and metastasis. The activation of insulin receptors on neoplastic cells is more related to cell survival and mitogenesis rather than glucose uptake. $^{6}$ Several previous studies found an increase in IGF receptors in breast, colorectal, lung, ovarian, and thyroid cancers, where insulin is said to cause oxidative stress which will cause chronic inflammation, resulting in susceptible cells and DNA damage. leading to cell mutase. ${ }^{11,34}$

Hyperglycemia conditions will induce IGF stimulating the proliferation of vascular smooth muscle cells. ${ }^{35}$ Although this process is a pathophysiology of atherosclerosis, abnormal blood vessel growth can also cause cancer. Hyperinsulinemia in premenopause will increase the synthesis of androgens in the ovaries and adrenals which is associated with an increased risk of postmenopausal breast cancer, endometrium, and possibly other cancers. ${ }^{6}$ In liver cancer, the thing that might underlie this incident is exposure of liver cells to high concentrations of insulin related to portal circulation. $^{9}$

Apart from the condition of diabetes tyoe 2, hyperinsulinemia also thought to play an important role in the development of cancer in GDM. A study by Fuchs et al on 100.000 patients followed for 12 years showed that patients with GDM increased their risk of developing endometrial, ovarian, breast and cervical cancer by $70 \%{ }^{36}$ A similar result was found by Park et al that GDM was said to increase the risk of breast cancer by $68 \% .{ }^{37}$ In contrast, research by Bejaimal et al shows that although 
GDM increases the risk of developing thyroid cancer, it reduces the risk of developing breast cancer. ${ }^{38}$ Research reported GDM reduce the risk of developing breast cancer was also reported by Powe et al, Brandt et al, and Xie et al. ${ }^{39,41}$ Recent research related to the history of GDM as a risk factor for cancer needs to be done.

\section{Chronic inflammation}

Diabetes and inflammation can be a bidirectional relationship, where diabetes is said to be a chronic inflammatory disease. It also said to generate inflammation which is marked by an increase in IL-1, TNF- $\alpha$, or other pro-inflammatory cytokines such as chemokines, growth factors, free radicals, prostaglandins, and proteolytic enzymes. ${ }^{42}$ This condition will cause a micro environment that supports the growth of tumor cells such as macrophages, neutrophils, lymphocytes, dendritic cells, natural killer cells, fibroblasts, adipocytes and endothelial cells. ${ }^{42,43}$ Some of these factors work directly on cancer cells, by increasing proliferation, avoiding apoptosis and causing cell mutations. ${ }^{42}$ Although TNF- $\alpha$ is an important mediator of the antitumor immune response, chronic exposure to TNF- $\alpha$ will activate a series of signalling pathways, such as NF- $\kappa B$, mitogen protein kinase activation, and Jun kinase, which will prevent cell apoptosis and accelerate the growth and metastasis of cancer cells. ${ }^{44}$ Studies show that at least $20 \%$ of cancers are caused by chronic inflammation, inflammation by tumor cells is also thought to be involved in most solid tumors including colorectal cancer. $^{45,46}$

\section{Genetic variants}

Genetic variants are believed as factor related to cancer in diabetic patients. ${ }^{47}$ The Transcription factor 7 like 2 (TCF7L2) gene is found in both diabetes and cancers such as colorectal (48-50), breast, liver, prostate, lung, and glioma. ${ }^{39,45,46,51-53}$ Likewise with other genes such as CDKN2A/B, AKT2, PPARG, PTEN and HNF1B. ${ }^{46}$ Research related to the role of certain genes in diabetes as a risk factor for cancer needs to be done. This can later be used as an initial examination, predictor factors, or developed into therapy.

\section{Obesity}

Hyperinsulinemia is associated with obesity, where it is also dependently a risk factor for cancer.(34) Research by Iliana et al shows that obesity was present in $5.7 \%$ of cancer patients and estimated to increase related to latest lifestyle. ${ }^{10}$ Insulin resistance and inflammation will induce lipolysis by white adipose tissue which is causes a high release of free fatty acids into the plasma and associates with the growth of cancer cells. ${ }^{54}$ Research by Emma et al shows that adiposity is a most likely contributing factor to developing cancer in patients with diabetes. ${ }^{47}$
Adipose tissue is capable of producing free fatty acids, interleukin-6 (IL-6), where IL-6 is can activating signal transducer and activator of transcription protein, monocyte chemoattractant protein, plasminogen activator inhibitor-1 (PAI-1) which is associated with poor prognosis in breast cancer patients. ${ }^{6}$ Adipose will also increase the production of TNF- $\alpha$ which functions to reduce adiponectin levels. Adiponectin has a role to suppress inflammation and increase insulin sensitivity in cells, induce apoptosis through AMPK activation leading to activation of $\mathrm{p} 53, \mathrm{p} 21$, inhibiting proliferation. ${ }^{55,56}$ TNF- $\alpha$ also stimulates leptin production via HIF- $1 \alpha$. Leptin has a mitogenic effect which is believed to be the cause of the proliferation of breast, prostate and esophageal cancer cells. ${ }^{57}$ This allows a role in mutation of normal cells and regulates the development of cancer cells.

\section{Hyperlactatemia}

Hyperlactatemia is one of several factors that bridge diabetes and cancer. $^{58}$ Lactate is produced in the cytoplasm via glycolysis, through the reduction of intermediate metabolite pyruvate. ${ }^{59}$ Diabetes will increases glycolysis activity through the enzymes phosphofrukkinase and pyruvate dehydrogenase due to insulin resistance, hyperglycemia and hyperinsulinemia. ${ }^{60-62}$ In addition, insulin resistance will cause a decrease in glycogen synthesis and glucose oxidative metabolism leading to lactate accumulation. Lactate is able to facilitate the intrinsic effect of cancer cells on metabolism and induce tumorigenesis in normal cells. In addition, lactate also acts as a signalling molecule that can stimulate inflammation and tumor angiogenesis. $^{63}$

Hyperlactatemia can also change the micro environment, causes acidosis, and is associated with immunosuppression. LDH examination has long been used to assess prognosis in cancer patients. ${ }^{58}$ Although this condition is a bidirectional relationship, which cancer will also cause hyperlactatemia, its role as a risk factor for cancer in diabetes patients is a hypothesis that might be accepted regarding the pathophysiology described. Further research on LDH examination in cancer patients with diabetes needs to be done as epidemiological data which can later become the basis for examinations and therapy to reduce patient morbidity and mortality.

\section{Morbidity and mortality in cancer related to diabetes}

The systematic review and meta-analysis study by Bethany et al showed that diabetes can increase mortality in patients with cancer. ${ }^{64}$ It was also shown by the study of Lorraine et al that breast cancer patients with comorbidities diabetes had a higher mortality rate of 1.39 times. ${ }^{65}$ Research by Ballotari et al shows that the mortality rate in cancer patients with diabetes is 4 times higher than without diabetes. ${ }^{12}$ Regarding the relationship between diabetes and obesity, a study by Gallagher et al 
shows that an increase in BMI is said to be in line with an increased risk of death in almost all types of cancer. ${ }^{66}$

Diabetes is responsible to patients mortality and morbidity through the hyperinsulinemia and hyperglycemia as it increase proliferation of cancer cells and also risk of metastasis. ${ }^{64}$ Diabetes also increases the mortality of cancer patients related to other conditions such as cardiovascular disease, chronic kidney disease, secondary infection, and when undergo surgery. ${ }^{67-69}$ Study from Xiao et al in liver cancer patients with diabetes shows that the high mortality rate is also caused by other factors such as hepatitis and alcohol consumption. ${ }^{70}$

\section{CONCLUSION}

Although diabetes type 2 is more associated with a possible association with cancer, other types of diabetes such as diabetes type 1 and GDM also have a risk of developing cancer through mechanisms such as gene factors, hyperglycaemia, and chronic inflammation. Research related to diabetes and cancer in particular needs to be done. Blood glucose examination in cancer patients as well as cancer screening in diabetes patients need to be done to detect early incidence and reduce morbidity and mortality.

\section{ACKNOWLEDGEMENTS}

The Authors are responsible for this study and also reports there is no conflicts of interest in this work.

Funding: No funding sources Conflict of interest: None declared

Ethical approval: Not required

\section{REFERENCES}

1. Bao C, Pedersen NL, Yang R, Marseglia A, Xu W, Wang Y, et al. Diabetes in midlife and risk of cancer in late life: A nationwide Swedish twin study. Int J Cancer. 2018;143(4):793-800.

2. Bray F, Ferlay J, Soerjomataram I, Siegel RL, Torre LA, Jemal A. Global cancer statistics 2018: GLOBOCAN estimates of incidence and mortality worldwide for 36 cancers in 185 countries. CA Cancer J Clin. 2018;68(6):394-424.

3. Hua F, Yu JJ, Hu ZW. Diabetes and cancer, common threads and missing links. Cancer Lett. 2016;374(1):54-61.

4. International Diabetes Federation [Internet]. IDF Diabetes Atlas, 9th edn. 2019 [cited 2020 Dec 23]. Available at: https://www.diabetesatlas.org.

5. Care D, Suppl SS. Classification and diagnosis of diabetes: Standards of Medical Care in Diabetes2020. Diabetes Care. 2020;43:S14-31.

6. Giovannucci E, Harlan DM, Archer MC, Bergenstal RM, Gapstur SM, Habel LA, et al. Diabetes and cancer: A consensus report. Diabetes Care. 2010;33(7):1674-85.

7. Scappaticcio L, Maiorino MI, Bellastella G, Giugliano D, Esposito K. Insights into the relationships between diabetes, prediabetes, and cancer. Endocrine. 2017;56(2):231-9.

8. Wojciechowska J, Krajewski W, Bolanowski M, Krecicki T, Zatoński T. Diabetes and Cancer: A Review of Current Knowledge. Exp Clin Endocrinol Diabetes. 2016;124(5):263-75.

9. Vigneri P, Frasca F, Sciacca L, Pandini G, Vigneri R. Diabetes and cancer. Endocr Relat Cancer. 2009;16(4):1103-23.

10. Lega IC, Wilton AS, Austin PC, Fischer HD, Johnson JA, Lipscombe LL. The temporal relationship between diabetes and cancer: A population-based study. Cancer. 2016;122(17):2731-8.

11. Saarela K, Tuomilehto J, Sund R, Keskimäki I, Hartikainen S, Pukkala E. Cancer incidence among Finnish people with type 2 diabetes during. Eur J Epidemiol. 2019;34(3):259-65.

12. Ballotari P, Vicentini M, Manicardi V, Gallo M, Ranieri CS, Greci M, et al. Diabetes and risk of cancer incidence: Results from a population-based cohort study in northern Italy. BMC Cancer. 2017;17(1):1-8.

13. Pitot HC. The molecular biology of carcinogenesis. Cancer. 1993;72(3 S):962-70.

14. Sutandyo N. Diabetes Mellitus as One of the Risk Factors Contribute to Carcinogenesis. Indones $\mathbf{J}$ Cancer. 2020;14(2):64.

15. Wang M, Yang Y, Liao Z. Diabetes and cancer: Epidemiological and biological links. World $\mathbf{J}$ Diabetes. 2020;11(6):227-38.

16. Huxley R, Ansary-Moghaddam A, Berrington De González A, Barzi F, Woodward M. Type-II diabetes and pancreatic cancer: A meta-analysis of 36 studies. Br J Cancer. 2005;92(11):2076-83.

17. Jing W, Jin G, Zhou X, Zhou Y, Zhang Y, Shao C, et al. Diabetes mellitus and increased risk of cholangiocarcinoma: a meta-analysis. Eur J Cancer Prev. 2012;21(1):24-31.

18. Luo S, Li JY, Zhao LN, Yu T, Zhong W, Xia ZS, et al. Diabetes mellitus increases the risk of colorectal neoplasia: An updated meta-analysis. Clin Res Hepatol Gastroenterol. 2016;40(1):110-23.

19. Larsson SC, Mantzoros CS, Wolk A. Diabetes mellitus and risk of breast cancer: a meta-analysis. Int J Cancer. 2007;121(4):856-62.

20. Person P. Otto warburg: "on the origin of cancer cells." Oral Surgery, Oral Med Oral Pathol. 1957;10(4):412-21.

21. Bellier J, Nokin MJ, Lardé E, Karoyan P, Peulen O, Castronovo V, et al. Methylglyoxal, a potent inducer of AGEs, connects between diabetes and cancer. Diabetes Res Clin Pract. 2019;148:200-11.

22. Ryu TY, Park J, Scherer PE. Hyperglycemia as a risk factor for cancer progression. Diabetes Metab J. 2014;38(5):330-6. 
23. Fukada T, Yamasaki S, Nishida K, Murakami M, Hirano T. Zinc homeostasis and signaling in health and diseases. J Biol Inorg Chem. 2011;16(7):112334.

24. Pirola L, Balcerczyk A, Okabe J, El-Osta A. Epigenetic phenomena linked to diabetic complications. Nat Rev Endocrinol. 2010;6(12):665-75.

25. $\mathrm{Xu} \mathrm{J,} \mathrm{Ye} \mathrm{Y,} \mathrm{Wu} \mathrm{H,} \mathrm{Duerksen-Hughes} \mathrm{P}$, Zhang $\mathrm{H}$, $\mathrm{Li}$ P, et al. Association between markers of glucose metabolism and risk of colorectal cancer. BMJ Open. 2016;6(6).

26. Hanahan D, Weinberg RA. Hallmarks of cancer: The next generation. Cell. 2011;144(5):646-74.

27. Li Zyue, Yang Y, Ming M, Liu B. Mitochondrial ROS generation for regulation of autophagic pathways in cancer. Biochem Biophys Res Commun. 2011;414(1):5-8.

28. Godsland IF. Insulin resistance and hyperinsulinaemia in the development and progression of cancer. Clin Sci. 2010;118(5):31532.

29. Denley A, Carroll JM, Brierley GV, Cosgrove L, Wallace J, Forbes B, et al. Differential Activation of Insulin Receptor Substrates 1 and 2 by Insulin-Like Growth Factor-Activated Insulin Receptors. Mol Cell Biol. 2007;27(10):3569-77.

30. Vigneri R, Goldfine ID, Frittitta L. Insulin, insulin receptors, and cancer. J Endocrinol Invest. 2016;39(12):1365-76.

31. Pollak MN, Schernhammer ES, Hankinson SE. Insulin-like growth factors and neoplasia. Nat Rev Cancer. 2004;4(7):505-18.

32. Wong KK, Engelman JA, Cantley LC. Targeting the PI3K pathway in cancer. Curr Opin Genet Dev. 2009;8(8):627-44.

33. Zoncu R, Efeyan A, Sabatini DM. MTOR: From growth signal integration to cancer, diabetes and ageing. Nat Rev Mol Cell Biol. 2011;12(1):21-35.

34. Lega IC, Lipscombe LL. Review: Diabetes, Obesity, and Cancer-Pathophysiology and Clinical Implications. Endocr Rev. 2020;41(1):33-52.

35. Clemmons DR, Maile LA, Ling Y, Yarber J, Busby WH. Role of the integrin $\alpha \mathrm{V} \beta 3$ in mediating increased smooth muscle cell responsiveness to IGF-I in response to hyperglycaemic stress. Growth Horm IGF Res. 2007;17(4):265-70.

36. Fuchs O, Sheiner E, Meirovitz M, Davidson E, Sergienko R, Kessous R. The association between a history of gestational diabetes mellitus and future risk for female malignancies. Arch Gynecol Obstet. 2017;295(3):731-6.

37. Park YMM, O'Brien KM, Zhao S, Weinberg CR, Baird DD, Sandler DP. Gestational diabetes mellitus may be associated with increased risk of breast cancer. Br J Cancer. 2017;116(7):960-3.

38. Bejaimal SAD, Wu CF, Lowe J, Feig DS, Shah BR, Lipscombe LL. Short-term risk of cancer among women with previous gestational diabetes: A population-based study. Diabet Med. 2016;33(1):3946.

39. Powe CE, Tobias DK, Michels KB, Chen WY, Eliassen H, Manson JE, et al. HHS Public Access. 2018;1-15.

40. Van Den Brandt PA, Spiegelman D, Yaun SS, Adami HO, Beeson L, Folsom AR, et al. Pooled analysis of prospective cohort studies on height, weight, and breast cancer risk. Am J Epidemiol. 2000;152(6):514-27.

41. Xie C, Wang W, Li X, Shao N, Li W. Gestational diabetes mellitus and maternal breast cancer risk: a meta-analysis of the literature. J Matern Neonatal Med. 2019;32(6):1022-32.

42. Lori M. Millner, Mark W. Linder and RVJ. HHS Public Access. Physiol Behav. 2019;176(3):139-48.

43. Crusz SM, Balkwill FR. Inflammation and cancer: Advances and new agents. Nat Rev Clin Oncol. 2015;12(10):584-96.

44. Berraondo P, Sanmamed MF, Ochoa MC, Etxeberria I, Aznar MA, Pérez-Gracia JL, et al. Cytokines in clinical cancer immunotherapy. $\mathrm{Br} \mathbf{J}$ Cancer. 2019;120(1):6-15.

45. Grivennikov SI, Wang K, Mucida D, Stewart CA, Schnabl B, Jauch D, et al. IL-23/IL-17-mediated tumour growth. Nature. 2013;491(7423):254-8.

46. Purrington KS, Slager S, Eccles D, Yannoukakos D, Fasching PA, Miron P, et al. Genome-wide association study identifies 25 known breast cancer susceptibility loci as risk factors for triple-negative breast cancer. Carcinogenesis. 2014;35(5):1012-9.

47. Vincent EE, Yaghootkar H. Using genetics to decipher the link between type 2 diabetes and cancer: shared aetiology or downstream consequence? Diabetologia. 2020;63(9):1706-17.

48. Folsom AR, Pankow JS, Peacock JM, Bielinski SJ, Heiss G, Boerwinkle E. Variation in TCF7L2 and Increased Risk of Colon Cancer: The Atherosclerosis Risk in Communities (ARIC) Study. Diabetes Care. 2008;31(5):905-9.

49. Freeman. HHS Public Access. Physiol Behav. 2018;176(1):139-48.

50. Zhang B, Jia W, Matsuda K, Kweon S, Matsuo K, Xiang B, et al. HHS Public Access. 2014;46(6):53342.

51. Burwinkel B, Shanmugam KS, Hemminki K, Meindl A, Schmutzler RK, Sutter C, et al. Transcription factor 7-like 2 (TCF7L2) variants is associated with familial breast cancer risk: A casecontrol study. BMC Cancer. 2006;6:7-10.

52. Michailidou K, Hall P, Gonzalez-Neira A, Ghoussaini M, Milne RL, Schmidt MK, et al. NIH Public Access. 2014;45(4):353-61.

53. Agalliu I, Suuriniemi M, Prokunina-Olsson L, Johanneson B, Collins FS, Stanford JL, et al. Evaluation of a variant in the transcription factor 7like 2 (TCF7L2) gene and prostate cancer risk in a population-based study. Prostate. 2008;68(7):740-7. 
54. Iyengar NM, Hudis CA, Dannenberg AJ. Obesity and cancer: Local and systemic mechanisms. Annu Rev Med. 2015;66:297-309.

55. Renehan AG, Zwahlen M, Egger M. Adiposity and cancer risk: New mechanistic insights from epidemiology. Nat Rev Cancer. 2015;15(8):484-98.

56. Van Kruijsdijk RCM, Van Der Wall E, Visseren FLJ. Obesity and cancer: The role of dysfunctional adipose tissue. Cancer Epidemiol Biomarkers Prev. 2009;18(10):2569-78.

57. Somasundar $\mathrm{P}, \mathrm{Yu}$ AK, Vona-Davis L, McFadden DW. Differential effects of leptin on cancer in vitro. J Surg Res. 2003;113(1):50-5.

58. Wu Y, Dong Y, Atefi M, Liu Y, Elshimali Y, Vadgama JV. Lactate, a Neglected Factor for Diabetes and Cancer Interaction. Mediators Inflamm. 2016;2016.

59. Romero-Garcia S, Moreno-Altamirano MMB, Prado-Garcia H, Sánchez-García FJ. Lactate contribution to the tumor microenvironment: Mechanisms, effects on immune cells and therapeutic relevance. Front Immunol. 2016;7.

60. Thorburn AW, Gumbiner B, Bulacan F, Wallace P, Henry RR. Intracellular glucose oxidation and glycogen synthase activity are reduced in noninsulin-dependent (type II) diabetes independent of impaired glucose uptake. J Clin Invest. 1990;85(2):522-9.

61. Bokhari S, Emerson P, Israelian Z, Gupta A, Meyer C. Metabolic fate of plasma glucose during hyperglycemia in impaired glucose tolerance: Evidence for further early defects in the pathogenesis of type 2 diabetes. Am J Physiol Endocrinol Metab. 2009;296(3):440-4.

62. DeFronzo RA. Insulin resistance, lipotoxicity, type 2 diabetes and atherosclerosis: The missing links. The Claude Bernard Lecture 2009. Diabetologia. 2010;53(7):1270-87.
63. Feichtinger RG, Lang R. Targeting L-Lactate Metabolism to Overcome Resistance to Immune Therapy of Melanoma and Other Tumor Entities. J Oncol. 2019.

64. Barone BB, Yeh HC, Snyder CF, Peairs KS, Stein $\mathrm{KB}$, Derr RL, et al. Long-term all-cause mortality in cancer patients with preexisting diabetes mellitus: A systematic review and meta-analysis. JAMA - J Am Med Assoc. 2008;300(23):2754-64.

65. Lipscombe LL, Goodwin PJ, Zinman B, McLaughlin JR, Hux JE. The impact of diabetes on survival following breast cancer. Breast Cancer Res Treat. 2008;109(2):389-95.

66. Gallagher EJ, LeRoith D. Obesity and diabetes: The increased risk of cancer and cancer-related mortality. Physiol Rev. 2015;95(3):727-48.

67. Ranc K, Jørgensen ME, Friis S, Carstensen B. Mortality after cancer among patients with diabetes mellitus: Effect of diabetes duration and treatment. Diabetologia. 2014;57(5):927-34.

68. Baena-Díez JM, Peñafiel J, Subirana I, Ramos R, Elosua R, Marín-Ibañez A, et al. Risk of causespecific death in individuals with diabetes: A competing risks analysis. Diabetes Care. 2016;39(11):1987-95.

69. Tancredi M, Rosengren A, Svensson AM, Kosiborod M, Pivodic A, Gudbjörnsdottir S, et al. Excess Mortality among Persons with Type 2 Diabetes. N Engl J Med. 2015;373(18):1720-32.

70. Ge XJ, Du YX, Zheng LM, Wang M, Jiang JY. Mortality trends of liver cancer among patients with type 2 diabetes at the global and national level. J Diabetes Complications. 2020;34(8):107612.

Cite this article as: Tedjamartono TD. Diabetes as the risk of cancer: a literature review. Int J Res Med Sci 2021;9:935-42. 